
\title{
25 Research Suare \\ Effect of pile driving on ground vibration in clay soil: Numerical and experimental study
}

\section{Hirad Shamimi Noori}

Islamic Azad University South Tehran Branch

Reza Shirinabadi ( $\nabla$ re.shirinabadi@gmail.com )

south tehran branch

Ehsan Moosavi

Islamic Azad University South Tehran Branch

\section{Research Article}

Keywords: pile driving, ground vibration, peak particle velocity, experimental study, numerical modeling

Posted Date: August 5th, 2021

DOl: https://doi.org/10.21203/rs.3.rs-307663/v1

License: (1) This work is licensed under a Creative Commons Attribution 4.0 International License. Read Full License

Version of Record: A version of this preprint was published at Geotechnical and Geological Engineering on November 20th, 2021. See the published version at https://doi.org/10.1007/s10706-021-02010-8. 


\section{Abstract}

In this study, peak particle velocity (PPV) values for driving three piles with $40 \mathrm{~cm}, 50 \mathrm{~cm}$, and $70 \mathrm{~cm}$ in a clayey soil through the impact piling method are investigated by an experimental study and a numerical simulation. An experimental study is carried out on a scale of 1:20 of the operation. Numerical simulation is performed by using an axisymmetric model in PLAXIS 2D finite element software. Properties of the soil and the piles used in the experimental study are obtained from geotechnical tests and employed in the numerical simulation. The model has been verified by comparing the acquired PPV values with those measured in the experimental study. The results show a good agreement between the computed values and the field data. Moreover, measured peak particle velocities in the experimental study indicate that an increase in the diameter of the pile can increase the level of ground vibration. Some sensitivity analyses have been performed by numerical modeling to determine the effect of soil and pile properties on the changes of PPV. The results indicate that increase in friction angle of the soil and pile diameter and reduction in elastic modulus of soil will increase the level of ground vibration.

\section{Introduction}

In most of the construction operations where an adequate ground support is not available, pile diving for construction of foundations is required. Thus, it is essential to predict and estimate the PPV value of ground vibration induced by pile driving to prevent disturbing the residents and damages to the structures adjacent to the operation site.

Many researchers, including; Wiss (1981), Attewell et al. (1992), Lewis and Davie (1993), Massarsch and Fellenius (2008), Massarsch and Fellenius (2014 a,b), and Deckner et al. (2017) have investigated the ground vibrations resulting from impact pile driving method and presented various equations for estimation of the peak particle velocity (PPV) value and particle image velocimetry (Jiang et al. 2020). Most of the abovementioned researchers concluded that attenuation of ground vibration is dependent to the hammer impact force and the radial distance from the vibration source. However, Massarsch and Fellenius (2008) presented other equations for estimation of the level of ground vibrations due to impact pile driving. They concluded that ground vibration due to pile driving is based on three different waves. Spherical waves that are generated from the pile toe, cylindrical waves which are emitted from the pile shaft and Rayleigh waves which are generated from the interaction of these two waves on the ground surface. In addition to these waves, dynamic soil resistance at shaft and toe of the pile have to be taken into account for estimation of level of ground vibration due to impact pile driving. Field study is counted as another method of estimating and predicting the ground vibrations caused by pile driving. In this method, propagation of ground vibrations induced from pile driving is investigated by measuring and analyzing the peak particle acceleration or peak particle velocity of vibrations at specified distances from the pile driving operation. Various studies have been conducted in this area, including studies by Kim and Lee (1999), (Hadjuk et al. 2004), (Dungca et al. 2016). 
In addition to the aforementioned methods, experimental study in small scale has been done by researchers like; (Musir and Abdul Ghani (2013), Mahmood and Abdulrahman (2017) to inspect the ground vibrations caused by pile driving. Musir and Abdul Ghani (2013) investigated the effects of various parameters in propagation of ground vibrations that affect the surrounding structures by means of a scaled laboratory test. The soil used in their study was river sand and the piles were squared piles with $7.5 \mathrm{~mm} \times 7.5 \mathrm{~mm}$, and $10 \mathrm{~mm} \times 10 \mathrm{~mm}$ diameters and the length of $300 \mathrm{~mm}$. The hammer weight and the height of fall were considered $1200 \mathrm{~g}$ and $150 \mathrm{~mm}$, respictively. Results of their study showed that the vibration at the bottom of the building were higher than the top of the building and the highest value for particle velocity was recorded at the points close to the piles. Moreover, researchers found that smaller piles generate more vibrations at the top of the structures.

In this regard, Mahmood and Abdulrahman (2017) practiced an experimental study in small scale and considered a concrete pile with dimensions of $20 \mathrm{~mm} \times 20 \mathrm{~mm}$ and a container made of steel in dimensions of $1200 \mathrm{~mm} \times 1200 \mathrm{~mm} \times 900 \mathrm{~mm}$ to evaluate the changes in the values of PPV at the distances $2.5 d, 5 d, 10 d, 17 d, 20 d$ and $25 d$ from the pile. A sandy soil was used in their study. The hammer weight was $1.68 \mathrm{~kg}$ and the hammer height of fall was considered $279 \mathrm{~mm}$. The results indicated that the maximum particle velocity was recorded at the points close to the pile and at the penetration depths of $20 \mathrm{~cm}$ to $24 \mathrm{~cm}$.

In the recent decades, due to an increasing development in numerical analysis of geotechnical problems, use of geotechnical software's to investigate the propagation and attenuation of ground vibrations caused by pile driving has become more popular. In this regard, Masoumi et al. (2007) developed a numerical model using the Finite Element-Boundary Element model by ABAQUS software to predict the inductive ground vibrations from installation of piles through vibratory and impact pile driving methods. In their analysis, soil medium was considered elastic with hysteresis damping and separation between the soil medium and the pile had been neglected. In case of impact pile driving, the results showed that body waves were attenuated at points located far from the pile and Rayleigh waves, independent of the penetration depth of the pile, had the most influence on the ground vibrations at the points on the ground surface. Masoumi et al. (2009) performed another study using the same FE-BE model by ABAQUS software. In this study, the non-linear behavior for the soil around the pile and also the dynamic interaction between the soil and the pile had been taken into account. Researchers concluded that this method presents more accurate results relating to the prediction of ground vibrations.

Madheswaran et al. (2009) analyzed the peak particle acceleration induced by a piling operation in a real condition through numerical modeling using finite element method by PLAXIS software. After verifying the results of their numerical modeling, researchers investigated the impact of concrete trenches on absorption of ground vibrations due to pile driving. The acquired results from numerical modeling indicated that the finite element analysis done by PLAXIS overestimated the peak particle acceleration about $20 \%$ more than the field data. By analyzing the obtained PPV from pile driving at different distances from the pile, researchers concluded that the presence of concrete-filled trenches at specific distances from the pile considerably affect the absorption of ground vibrations. 
Khoubani and Ahmadi (2012) simulated the continuous penetration of a pile to a desired depth, using the commercial code ABAQUS. In their study, the effects of plastic deformations around the pile and the frictional contact between the pile and the soil on the level of vibrations had been taken into account. Furthermore, continuous pile penetration modeling allowed the researchers to predict the magnitude of vibrations at different depths. The maximum value for particle velocity in their study was related to the penetration of the pile to the critical depth of penetration. Likewise, the PPV value was higher at lower depths, especially at points close to the pile. This value increased on the ground surface for points located at farther distances from the pile.

Recently, Rezaei et al. (2016) investigated the changes in the values of PPV at radial and vertical distances from impact pile driving operation by modeling the continuous penetration of the pile to the desired depth through ABAQUS software. They also investigated the effects of soil properties and pile geometry on the level of vibrations. The results indicated that the Mohr-Coulomb model can successfully simulate the pile penetration into the soil. An increase in cohesion and friction angle and a decrease in elastic modulus of soil increase the PPV value.

Most of the numerical studies on the ground vibrations due to impact pile driving have used the data presented by Masoumi et al. (2009) to validate the numerical modeling and compared the computed PPV values with those presented by Wiss (1981). On the other hand, experimental studies about inductive ground vibrations from impact pile driving method have been performed on sandy soils. In this study, ground vibration due to impact pile driving in a clayey soil is investigated through an experimental study in small simulating scale and also numerical modeling through finite element PLAXIS 2D software. To validate the results of numerical modeling, the soil and pile properties used in the experimental study have been extracted by implementing geotechnical tests and employed in the numerical modeling. Afterwards, the computed PPV values are compared to the field data. Moreover, sensitivity analysis is performed to determine the effects of pile geometry and soil properties on the level of ground vibration.

\section{Experimental Study}

In order to investigate the level of ground vibrations due to driving three piles with diameters of $40 \mathrm{~cm}$, $50 \mathrm{~cm}$ and $70 \mathrm{~cm}$ and the length of $600 \mathrm{~cm}$ in a clayey soil, an experimental study in scale of $1: 20$ of a hypothetical pile driving site with $28 \mathrm{~m}$ width is carried out. In this study, a clayey soil container is used to simulate the pile driving site and three wooden cylinders are utilized to simulate the piles. A steel box is also used as the pile driving hammer.

\subsection{Clayey soil container}


Due to simulating the pile driving process in scale of $1: 20$, the container used in this study is made in dimensions of $1.4 \mathrm{~m} 1 \mathrm{~m} 0.5 \mathrm{~m}$. Inside the container is insulated in order to prevent soil penetration into outer space and also to absorb the vibrations emitted from the hammer impact. Fig. 1 shows the clayey soil container. The container used in this study is similar to those used by (Musir and Abdul Ghani (2013), Mahmood and Abdulrahman (2017)).

\subsection{Piles used in experimental study}

For simulating the piles used in the hypothetical pile driving operation, three wooden cylinders in diameters of $2 \mathrm{~cm}, 2.5 \mathrm{~cm}$ and $3.5 \mathrm{~cm}$ and the length of $30 \mathrm{~cm}$ have been made to simulate the piles with diameters of $40 \mathrm{~cm}, 50 \mathrm{~cm}$, and $70 \mathrm{~cm}$ and the length of $600 \mathrm{~cm}$, respectively. Figs. 2-3 show the wooden cylinders made for the simulation of the piles.

\subsection{Simulated pile driving hammer}

The hammer weight considered for the current study was $1000 \mathrm{~g}$. Weight of the steel box with dimensions of $60 \mathrm{~mm} 60 \mathrm{~mm} 60 \mathrm{~mm}$ was $700 \mathrm{~g}$. So as to reach the required weight, a $300 \mathrm{~g}$ box has been attached to the steel box. The hammer height of fall has been considered $200 \mathrm{~mm}$. Fig. 4 shows the simulated pile driving hammer.

\subsection{Clayey soil deposit}

The soil used in this study is a clayey soil. The constituent elements of this soil have been identified through X-ray fluorescence test and presented in Table 1.

\subsection{Experimental study procedure}

In order to estimate the PPV values in predetermined distances from driving three piles into the soil, piles have been placed at the specified point. After inserting the pile, the seismograph (SPSEISW-3) sensors 
were located at $25 \mathrm{~cm}, 50 \mathrm{~cm}, 75 \mathrm{~cm}$ and $100 \mathrm{~cm}$ intervals from the pile. The next step involved placing a wooden box with $50 \mathrm{~cm}$ length around the pile to prevent the hammer from deviating from the pile head. Vibrations were measured for each blow, and this process continued until the full penetration of the pile into the soil. Fig. 5 illustrates the placement of sensors as well as the wooden box used to prevent the deviation of the hammer.

Table 1 Constituent elements of the clayey soil

\begin{tabular}{|c|c|}
\hline Element & Percentage (\%) \\
\hline $\mathrm{Na}_{2} \mathrm{O}$ & 0.63 \\
\hline $\mathrm{MgO}$ & 2.98 \\
\hline $\mathrm{Al}_{2} \mathrm{O}_{3}$ & 10.8 \\
\hline $\mathrm{SiO}_{2}$ & 50.1 \\
\hline $\mathrm{P}_{2} \mathrm{O}_{5}$ & 0.22 \\
\hline $\mathrm{So}_{3}$ & 0.26 \\
\hline $\mathrm{Cl}$ & 0.026 \\
\hline $\mathrm{K}_{2} \mathrm{O}$ & 2.52 \\
\hline $\mathrm{CaO}$ & 9.7 \\
\hline $\mathrm{TiO}_{2}$ & 0.70 \\
\hline $\mathrm{V}_{2} \mathrm{O}_{5}$ & 0.030 \\
\hline $\mathrm{MnO}$ & 0.16 \\
\hline $\mathrm{Fe} \mathrm{O}_{3}$ & 6.0 \\
\hline $\mathrm{Co}_{3} \mathrm{O}_{4}$ & 0.0064 \\
\hline $\mathrm{NiO}$ & 0.0057 \\
\hline $\mathrm{CuO}$ & 0.0066 \\
\hline $\mathrm{ZnO}$ & 0.015 \\
\hline $\mathrm{Rb}{ }_{2} \mathrm{O}$ & 0.0098 \\
\hline $\mathrm{SrO}$ & 0.046 \\
\hline $\mathrm{Y}_{2} \mathrm{O}_{3}$ & 0.0036 \\
\hline $\mathrm{BaO}$ & 0.048 \\
\hline $\mathrm{PbO}$ & 0.0029 \\
\hline
\end{tabular}

\subsection{Test results}

Peak vertical velocity (PVV) values for driving each pile into the depth of $30 \mathrm{~cm}$ through impact driving method was recorded with (SPSEISw-3) seismograph. After converting the units from $\mathrm{mV} / \mathrm{g}$ to $\mathrm{mm} / \mathrm{s}$, PVV values are shown in Fig. 6 . In this figure, PVV values are shown at depths of $5 \mathrm{~cm}, 10 \mathrm{~cm}, 15 \mathrm{~cm}, 25 \mathrm{~cm}$ and $30 \mathrm{~cm}$ from the ground surface. PVV value increased by reaching to the critical depth of penetration and it has been reduced by penetrating to the lower depths. The recorded particle velocities at each point are extracted from Fig. 6 and shown as PPV at specified distances from the pile in Fig. 7. 
The maximum PPV value recorded for penetration of all three piles was at the distance $25 \mathrm{~cm}$ from the piles and its value had a slump at distance $100 \mathrm{~cm}$ from the piles. The maximum rate of attenuation of ground vibration in penetration of all the piles to the desired depth was related to the distances $25 \mathrm{~cm}$ to $50 \mathrm{~cm}$ from the piles. After that, the trend of attenuation of ground vibration declined to slightly less than $2.5 \mathrm{~mm} / \mathrm{s}$. Among the piles tested in the current study, the highest value of PPV is related to the penetration of the pile with $3.5 \mathrm{~cm}$ diameter with the value of almost $22.5 \mathrm{~mm} / \mathrm{s}$. The PPV value diminished with a decrease in the diameter of the piles.

\section{Geotechnical Laboratory Tests}

Various geotechnical tests such as; direct shear test and uniaxial compressive strength test have been performed on the soil used in the experimental study to determine the friction angle, cohesion and elastic modulus of the soil. Fig. 8 shows the devices used in the laboratory tests.

To determine the elastic modulus of the pile with $2.5 \mathrm{~cm}$ diameter, a uniaxial compressive strength test has been performed on this pile as shown in Fig. 9 . The results of geotechnical tests on the soil and the pile are presented in Figs. 10-11 and Table 2.

Table 2 Properties of pile and soil used in experimental study

\begin{tabular}{|c|c|c|}
\hline Parameter & Clay & Pile with 2.5(cm) diameter \\
\hline Elastic modulus $\left(\mathrm{KN} / \mathrm{m}^{2}\right)$ & 5228 & 4165907 \\
\hline Poisson's ratio & 0.2 & 0.25 \\
\hline Density $\left(\mathrm{KN} / \mathrm{m}^{3}\right)$ & 18 & 25 \\
\hline Cohesion $\left(\mathrm{KN} / \mathrm{m}^{2}\right)$ & 1 & - \\
\hline Friction angle $($ ) & 28 & - \\
\hline
\end{tabular}

\section{Numerical Simulation Of Impact Pile Driving}

Numerical simulation has been performed by means of PLAXIS 2D software. This software is capable of modelling and analysing static and dynamic geotechnical problems in two forms, i.e. plain-strain and axisymmetric. A 15-nodded axisymmetric model is used in this study. Half of the pile and the medium are modelled in the numerical simulation. The pile has a diameter of $50 \mathrm{~cm}$ and a length of $6 \mathrm{~m}$, which only $25 \mathrm{~cm}$ of its diameter has been modelled due to numerical simulation in axisymmetric form. To estimate the PPV values at distances $5 \mathrm{~m}$ to $20 \mathrm{~m}$ from the pile driving operation, width of the model has been extended to 28 meters. In dynamic analysis of pile driving through PLAXIS 2D, Pile is embedded into the desired depth and a distributed dynamic load is applied on the pile head. Interface element has been employed at the contact area between the pile and the soil. Boundaries are set in two forms; standard fixities on both sides and the bottom of the model to prevent deformations around the model and dynamic absorbent boundaries to prevent reflection of seismic waves into the model (see Fig. 12). 
Mohr-Coulomb model is assumed for the soil and linear-elastic model is used for modelling the pile. Since the estimation of level of ground vibration has been considered, pile is regarded as a rigid body which transfers the energy generated from impact of the hammer to the pile head into the surrounding soil (Khoubani and Ahmadi 2012). Properties of the soil and the pile with $2.5 \mathrm{~cm}$ diameter obtained from geotechnical tests (Table 2) have been used in the numerical simulation. Mesh generation is done as medium in points located far from the pile and in areas close to the pile; mesh generation is done as fine (see Fig. 13). The calculations consist of three phases of plastic analysis, dynamic analysis at the time of the hammer impact to the pile head, and the second dynamic analysis phase for a complete dynamic cycle. The amount of applied force on the pile head and the duration of the dynamic cycles are selected based on the aforementioned experimental study on this pile in scale of 1:20. PPV values are extracted from the velocity-time curve for points located at $5 \mathrm{~m}, 10 \mathrm{~m}, 15 \mathrm{~m}$ and $20 \mathrm{~m}$ from the pile (see Fig. 14).

\section{Verification Of The Model}

PPV values for driving a pile with $50 \mathrm{~cm}$ diameter to the depth of $6 \mathrm{~m}$ have been extracted from the velocity-time curve in PLAXIS software, shown in Fig. 14, for the points located at distances $5 \mathrm{~m}, 10 \mathrm{~m}$, $15 \mathrm{~m}$ and $20 \mathrm{~m}$ from the pile. Moreover, The PPV values recorded in the 1:20 scale experimental study on the same pile have been extracted from Fig. 7. These values are shown in Fig. 15. Both of the obtained PPV values are compared in Fig. 16.

Considering the Fig. 16, it can be seen that the PPV values within $5 \mathrm{~m}$ from the pile were approximately equal in both methods. Numerical study overestimated the PPV values about $21.2 \%$ at distances of 10 to $20 \mathrm{~m}$ from the pile. In general, the computed values are in good agreement with the field data.

\section{Sensitivity Analysis}

Sensitivity analysis was performed by means of numerical modelling to identify the effects of different parameters such as pile diameter and soil properties including; friction angle and elastic modulus on the changes in the level of ground vibration. In order to determine the effect of these parameters on the level of ground vibrations, an impact force of $1.5 \mathrm{MN}$ was considered in the numerical simulation. Piles used in the sensitivity analysis had $60 \mathrm{~cm}, 80 \mathrm{~cm}$ and $100 \mathrm{~cm}$ diameter.

\subsection{Elastic modulus of the soil}


Fig. 17 shows the PPV values due to the increase in the elastic modulus of the soil. The soil elastic modulus was considered $20 \mathrm{MPa}$ in the first analysis. $50 \%$ and $66.5 \%$ have been added to its amount in the subsequent analyses. By increasing the elastic modulus of the soil to $66.5 \%$ more than its initial value, $37.5 \%$ is diminished from the PPV value at the distance of $5 \mathrm{~m}$ from the pile. Most of the changes in level of ground vibration have been experienced at distances close to the pile, whereas the percentage of these changes has been almost the same at farther distances.

\subsection{Friction angle of the soil}

In order to study the changes in the level of ground vibration due to the changes in the friction angle of the soil, analyses have been done by considering 25,35 and 45 for the friction angle. Fig. 18 shows the PPV values for three friction angles used in the sensitivity analysis. With $28 \%$ increase in friction angle, the PPV value increased $6 \%$ within $5 \mathrm{~m}$ from the pile, and by increasing the friction angle to $45 \%$ more than its initial value, PPV increased by $11 \%$. Most of the changes in level of ground vibration due to variation of the friction angle were related to the points close to the pile and these changes were negligible at points located at distances far from the pile.

\subsection{Pile diameter}

The effect of pile diameter on the value of PPV is shown in Fig. 19. Diameters of the piles used in this analysis were $0.6 \mathrm{~m}, 0.8 \mathrm{~m}$ and $1 \mathrm{~m}$. With $25 \%$ and $40 \%$ increase in the diameter, the PPV value increased about $10 \%$ and $28 \%$ of its initial value at the distance of $5 \mathrm{~m}$ from the pile, respectively. A $0.2 \mathrm{~m}$ increase in the diameter of the pile, resulted to an approximately $30 \%$ increase in PPV value at distances 10 to $20 \mathrm{~m}$ from the pile. By increasing the pile diameter from $0.8 \mathrm{~m}$ to $1 \mathrm{~m}$, there was a $13.5 \%$ increase in the level of ground vibration.

\section{Conclusion}

In this study, estimation of level of ground vibration due to impact pile driving in a clayey soil has been done by implementation of an experimental study and also numerical simulation by means of finite element PLAXIS software. Properties of materials used in the experimental study were extracted from geotechnical tests and employed in the numerical simulation. The PPV values obtained from the experimental study were compared with the computed PPV values in numerical simulation and indicated a close agreement between the results of two methods. Moreover, sensitivity analyses were performed to 
identify the effects of different parameters on the level of ground vibration induced by pile driving. The results of this study are summarized as below:

- The proximity of the results acquired from the experimental study and numerical modelling indicates that the Mohr-Coulomb model in PLAXIS software can be used in dynamic analysis of pile driving.

- As the distance from the pile increases, the PPV value decreases. Highest attenuation rate of ground vibrations is related to the points close to the pile and as the distance from the pile increases, the attenuation trend levels out.

- The results obtained from the experimental study as well as the sensitivity analysis by numerical modelling showed an increase in PPV value due to an increase in the diameter of the pile.

- An increase in the elastic modulus of the soil will lead to a decrease in the level of ground vibration.

- An increase in the friction angle of the soil increases the level of ground vibration at the points close to the pile.

- Pile diameter and elastic modulus of soil have the greatest effect on the changes of PPV value and the friction angle of soil has the least effect on these changes.

- The effect of friction angle and elastic modulus of soil on the changes of PPV value are greater at points located close to the pile and at farther distances, level of ground vibration is under the influence of geometrical damping and independent to the changes in different parameters.

- An increase in the diameter of the pile causes a noticeable increase in the level of ground vibration at all the points.

\section{Declarations}

\section{Author contribution}

The main research targets were expanded by Hirad Shamimi noori and Reza Shirinabadi. Hirad Shamimi noori and Reza Shirinabadi established the models and calculated the results. Ehsan Moosavi analyzed the calculated results and edited the draft of manuscript. All authors replied to reviewers \& apos; comments and revised the final version.

\section{Data Availability}

The datasets generated during and/or analyzed during the current study are available from the corresponding author on reasonable request.

\section{Conflict of interest}

The authors declare that they have no known competing financial interests or personal relationships that could have appeared to influence the work reported in this paper.

\section{References}


Attewell, P.B., Selby, A.R., and OهDonnel, L. (1992), "Tables and graphs for the estimation of ground vibration from driven piling operations", Geotechnical \& Geological Engineering, 10, 61-85.

Brinkgreve, B.J. and Vermeer, P.A. (1998), PLAXIS Finite Element Code for Soil and Rock Analysis, A.A. Balkema Publishers, Delft, the Netherlands.

Deckner, F., Viking, K., and Hintze, S. (2017), "Wave Patterns in the Ground: Case Studies Related to Vibratory Sheet Pile Driving", Geotechnical \& Geological Engineering, 35, 2863-2878.

Dungca, J.R., Acosta, D.Y., Juego, M.B., Sanchez, H.M. and Sanchez, I.S. (2016), "The propagation behavior of pile driving induced vibration done on soil at varying distances and its effects on existing structures", International Journal of GEOMATE, 10(21), 1877-1883.

https://doi.org/10.21660/2016.21.5223.

Jiang, T., Wang, L., Zhang, J., Jia, H., and Pan, J. (2020), "Effect of water content on near-pile silt deformation during pile driving using PIV technology", Geomechanics and Engineering, 23(2).

Hajduk, E.L., Ledford, D.L. and Wright, W.B. (2004),"Pile driving vibration energy-attenuation relationships in the Charleston, South Carolina area", International Conference on Case Histories in Geotechnical Engineering. 20.

Khoubani, A. and Ahmadi, M.M. (2012), "Numerical study of ground vibration due to impact pile driving", Geotechnical Engineering, 167, 28-39._https://doi.org/10.1680/geng.11.00094.

Kim, D.S. and Lee, J.S. (2000), "Propagation and attenuation characteristics of various ground vibrations", Soil Dynamics and Earthquake Engineering, 19, 115-126. https://doi.org/10.1016/s02677261(00)00002-6.

Lewis, M.R. and Davie, J.R. (1993), "Vibration due to pile driving”, International Conference on Case Histories in Geotechnical Engineering.8.

Madheswaran, C.K., Natarajan, K., Sundaravadivlu, R. and Boominathan, A. (2009), "Effect of trenches on attenuation of ground vibration during pile driving", In: Vibration Problems ICOVP-2007 Unan, E., Sengupta, D., Banerjee, M.M., Mukhopadhyay, B. and Demiray, H. (eds). Springer Proceeding in Physics, 126, Dordrecht, the Netherlands, 231-238. https://doi.org/10.1007/978-1-4020-9100-1_24.

Mahmood, R.M. and Abdulrahman, SH. M. (2017), "Characteristics of vibration wave transmission within the soil due to driving precast concrete pile", International Journal of Current Engineering and Technology, 7(6), 2104-2108.

Massarsch, K.R. and Fellenius, B.H. (2008), "Ground vibrations induced by impact pile driving", Proceeding of the $6^{\text {th }}$ International Conference on Case Histories in Geotechnical Engineering, Arlington, VA, USA. 
Massarsch, K.R. and Fellenius, B.H. (2014a), "Ground vibrations from pile and sheet pile driving, Part 1, Building damage", Proceeding of the DFIEFFC International Conference on Piling and Deep Foundations, Stockholm.

Massarsch, K.R. and Fellenius, B.H. (2014b), "Ground vibrations from pile and sheet pile driving, Part 2, Review of vibration standards", Proceeding of the DFIEFFC International Conference on Piling and Deep Foundations, Stockholm.

Masoumi, H.R., Degrande, G. and Lombart, G. (2007), "Prediction of free field vibrations due to pile driving using a dynamic soil-structure interaction formulation", Soil Dynamics and Earthquake Engineering, 27(2), 126-143 https://doi.org/10.1016/j.soildyn.2006.05.005.

Masoumi, H.R., Francois, S. and Degrande, G. (2009), "A non-linear coupled Finite Element-Boundary Element model for the prediction of vibrations due to vibratory and impact pile driving", International Journal for Numerical and Analytical Methods in Geomechanics, 33(2), 245-

274. https://doi.org/10.1002/nag.719.

Musir, A.A. and Abdul Ghani, A.N. (2013), "Pile driving effect on nearby building", Third International Conference on Geotechnique, Construction Materials and Environment, Nagoya, Japan.

Rezaei, M., Hamidi, A. and Farshi Homayoun Rooz, A. (2016), "Investigation of peak particle velocity variations during impact pile driving process", Civil Engineering Infrastructures Journal, 49(1), 49-59.

Wiss, J.F. (1981), "Construction vibrations: state-of-the-art", Journal of geotechnical Engineering ASCE, 107(2), 167-181.

\section{Figures}

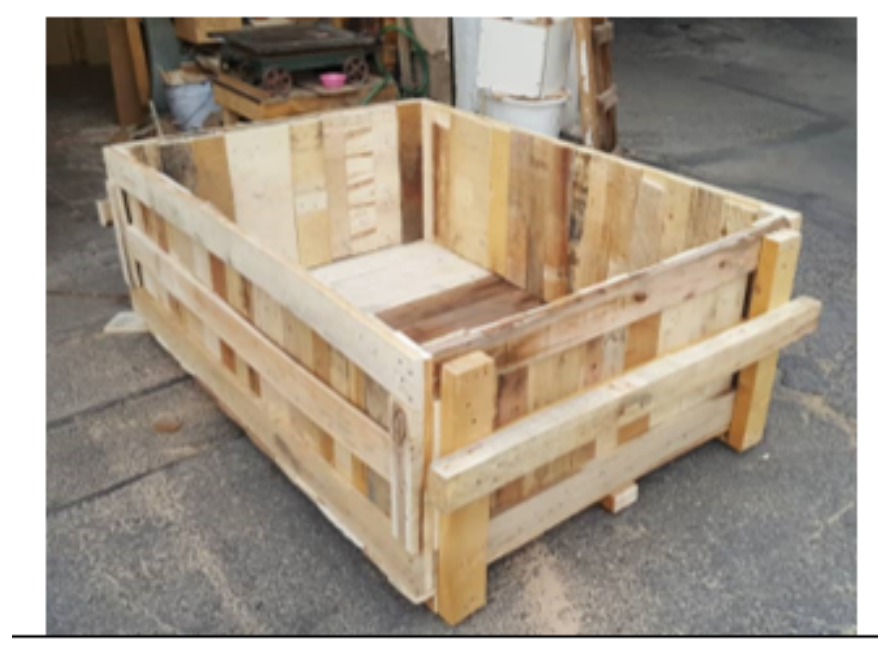

Figure 1

Clayey soil container used for simulation of pile driving in a clayey soil 


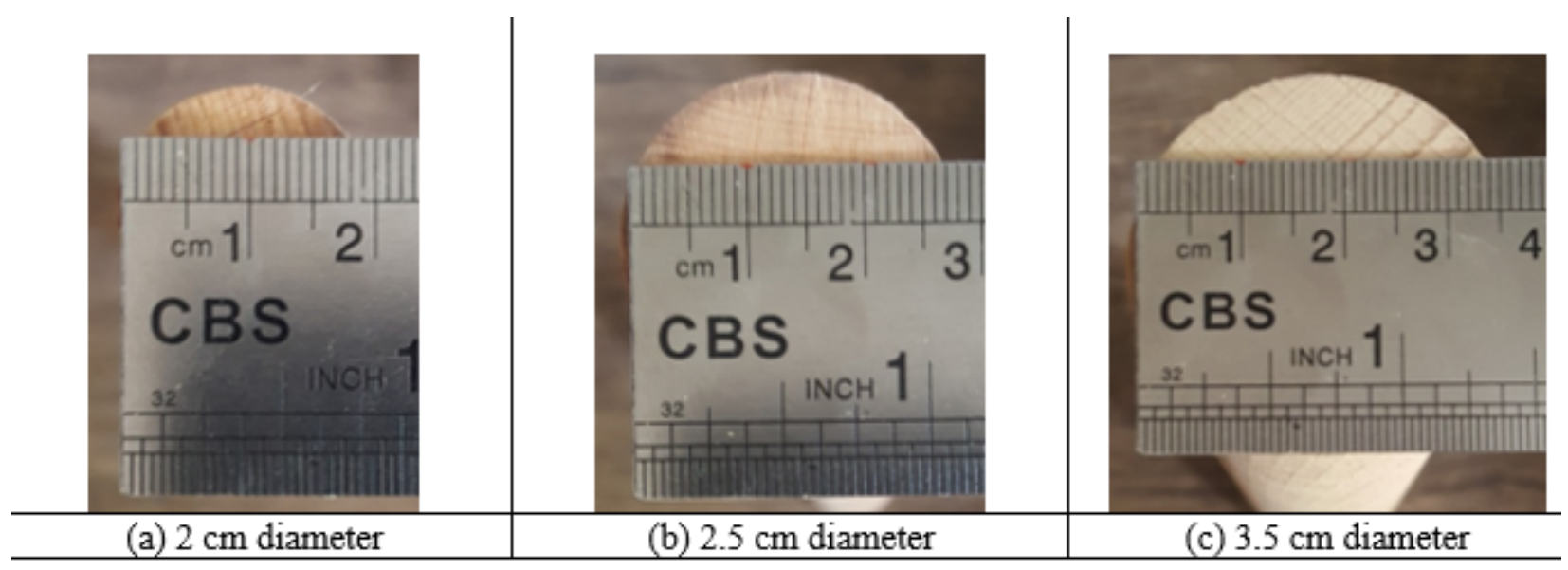

Figure 2

Diameters of wooden cylinders

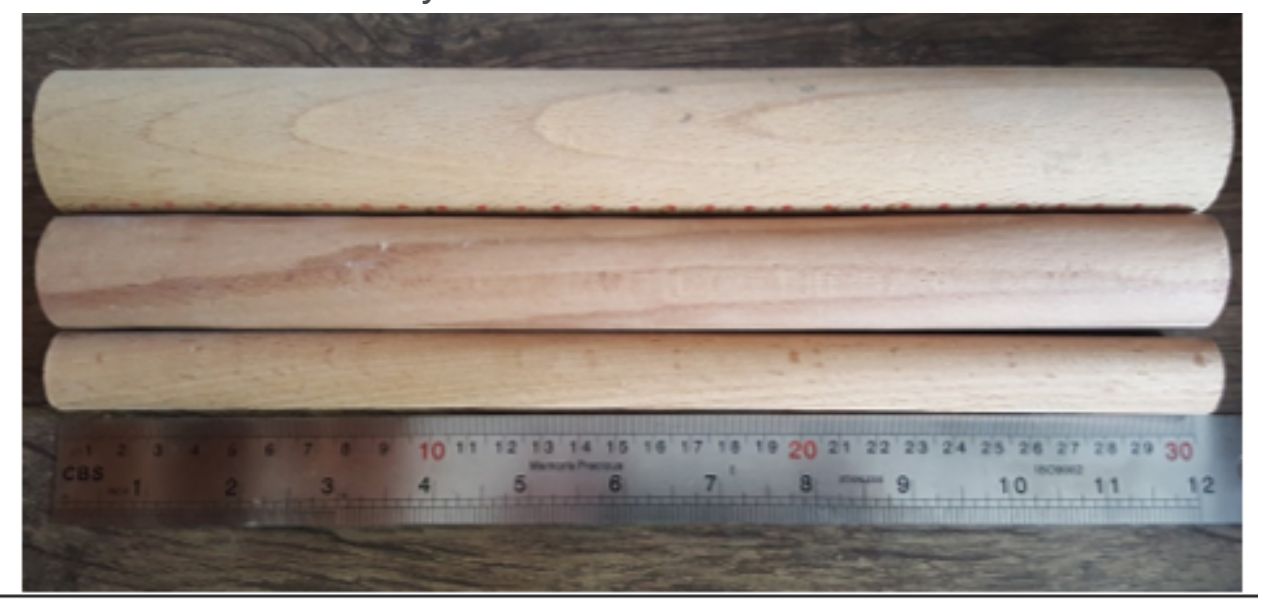

Figure 3

Length of wooden cylinders

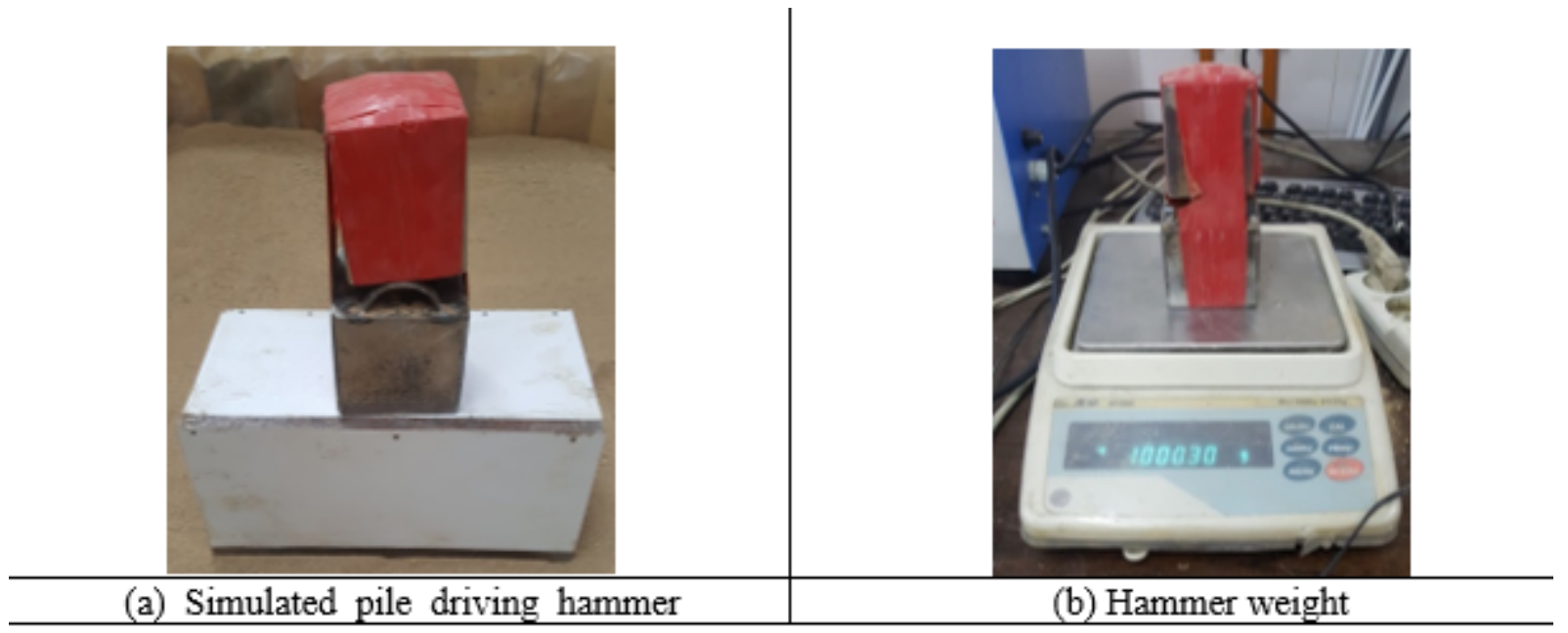

Figure 4

Simulated pile driving hammer 


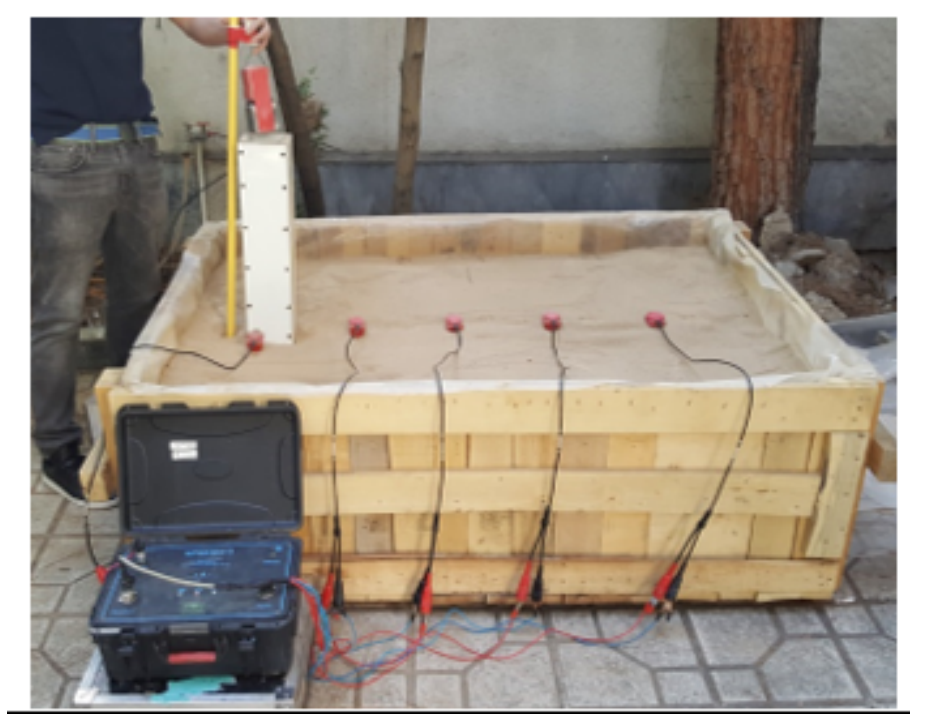

Figure 5

Placement of sensors and the wooden box
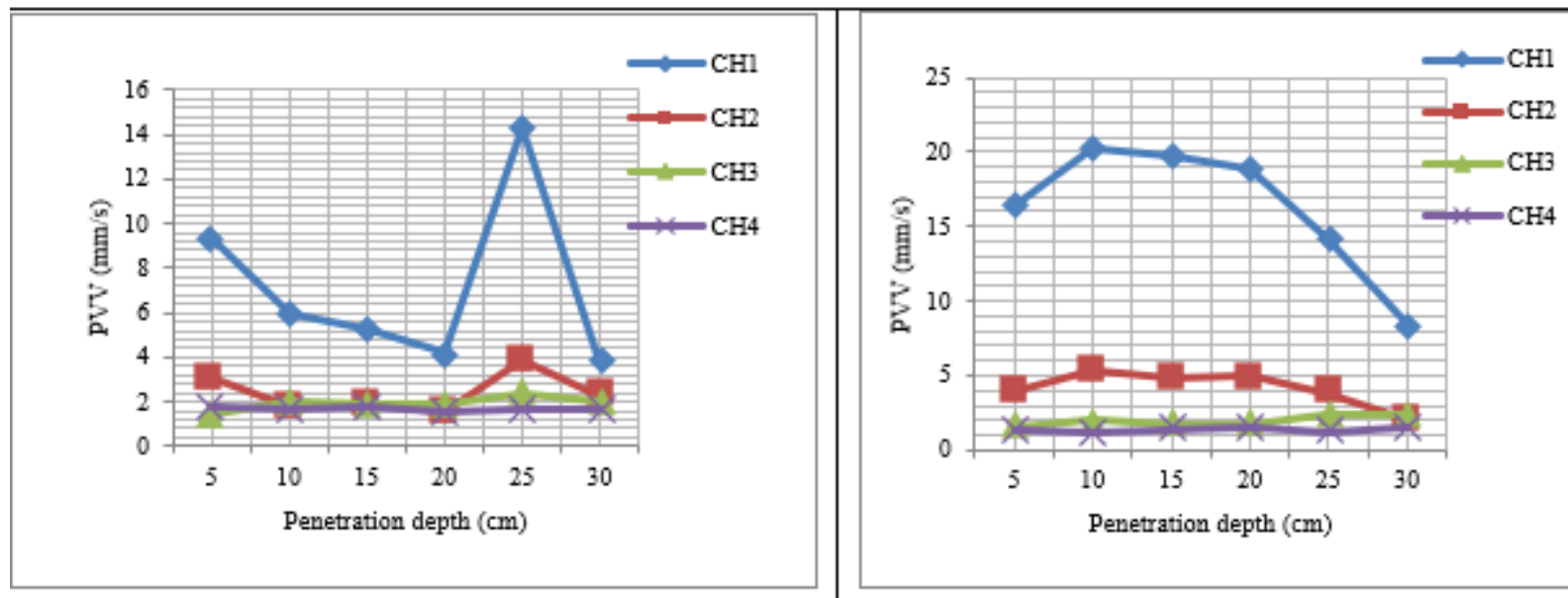

(a) PVV values for the pile with $2(\mathrm{~cm}) \mathrm{d}$

(b) PVV values for the pile with $2.5(\mathrm{~cm}) \mathrm{d}$
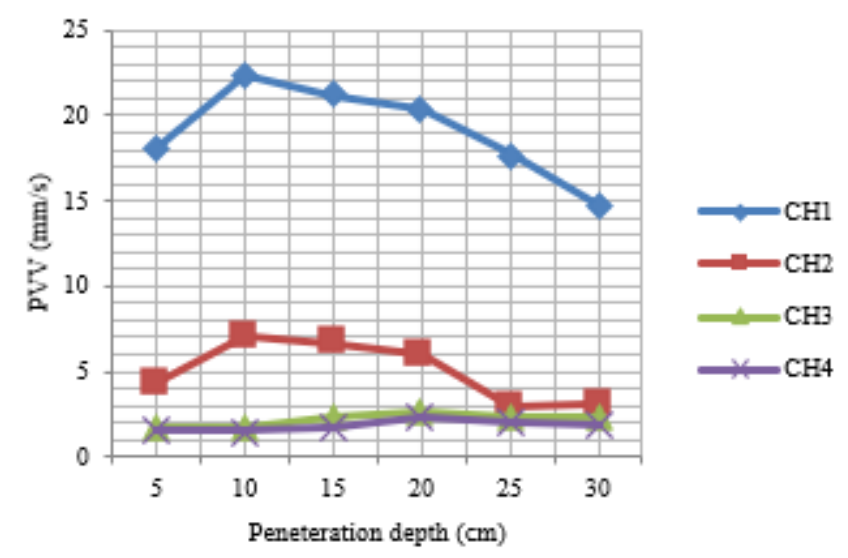

(c) PVV values for the pile with $3.5(\mathrm{~cm}) \mathrm{d}$

Figure 6 
Changes in PVV values

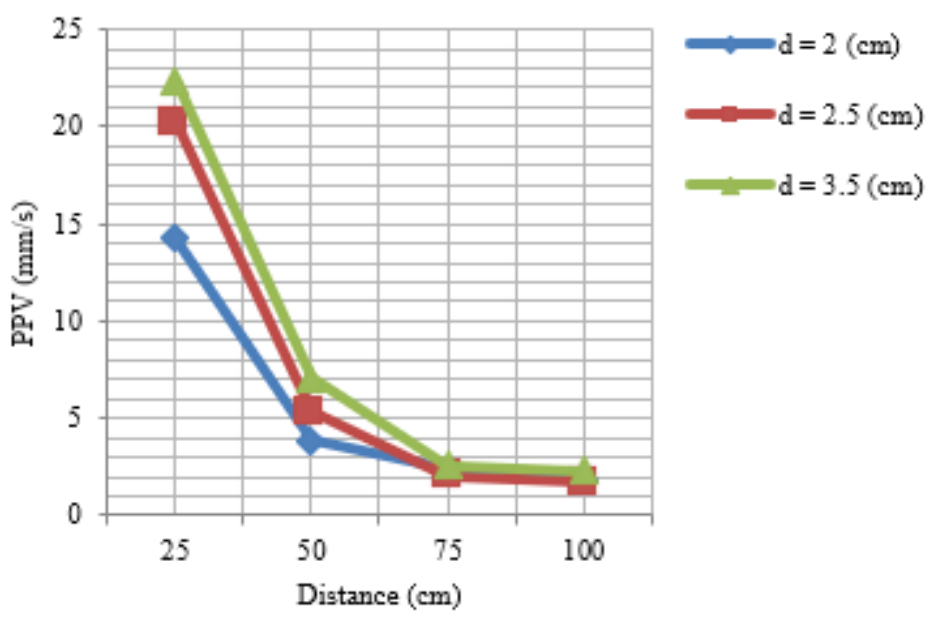

Figure 7

Obtained PPV values for penetration of three piles

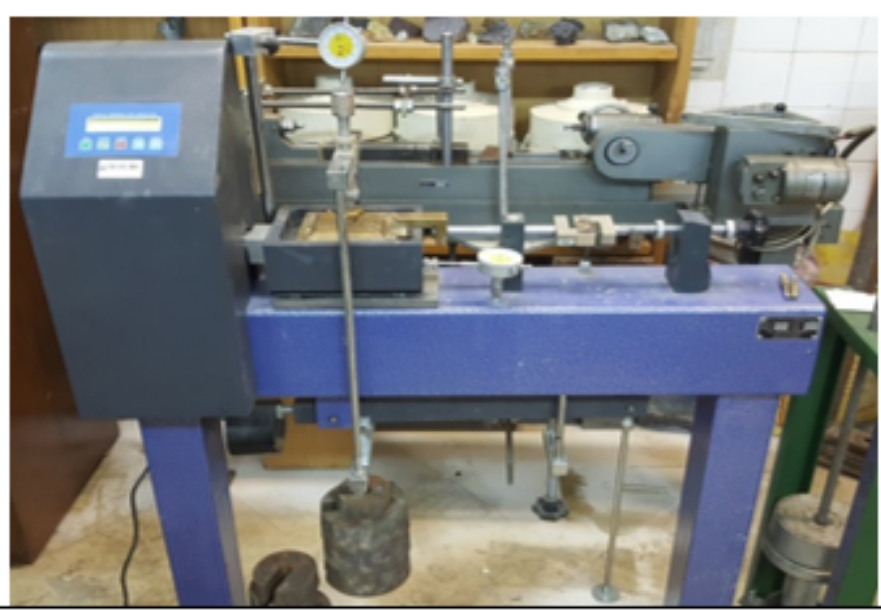

(a) Direct shear test

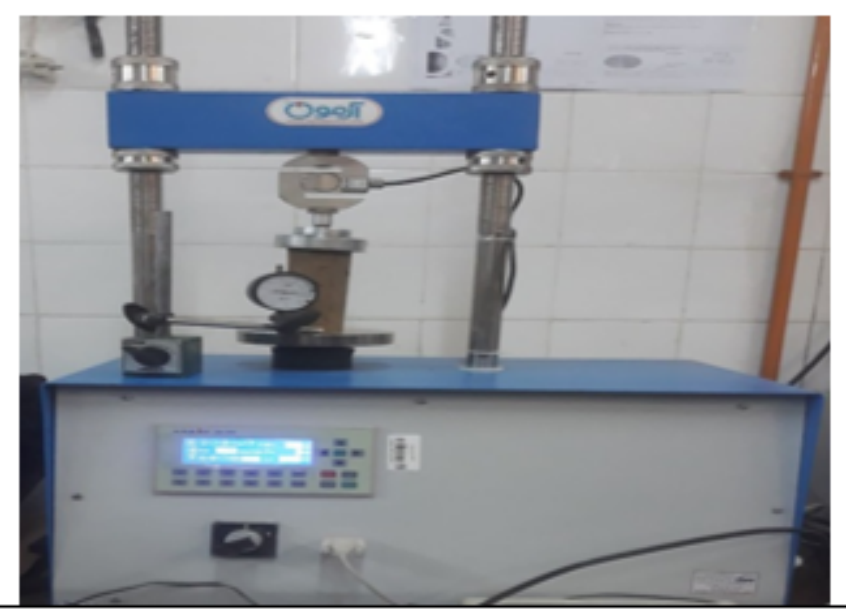

(b) Uniaxial compressive strength test

\section{Figure 8}

Geotechnical tests on the soil 


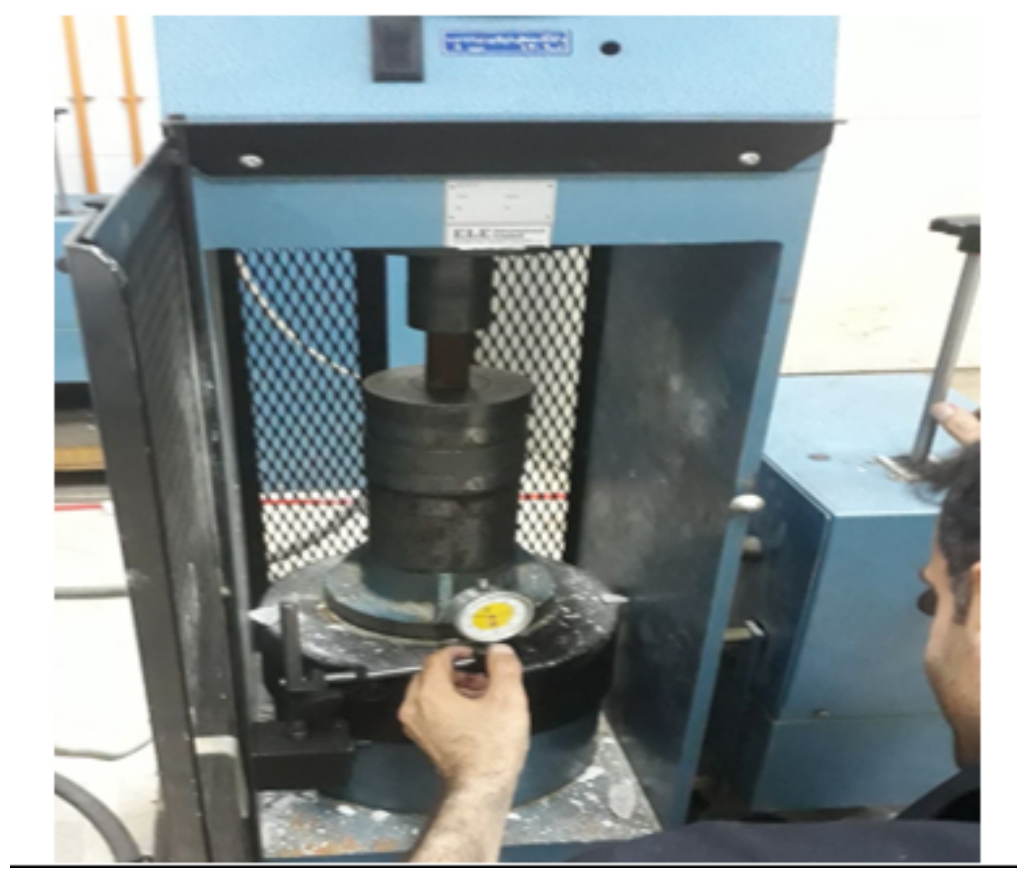

Figure 9

Uniaxial compressive strength test on the pile in $2.5 \mathrm{~cm}$ diameter

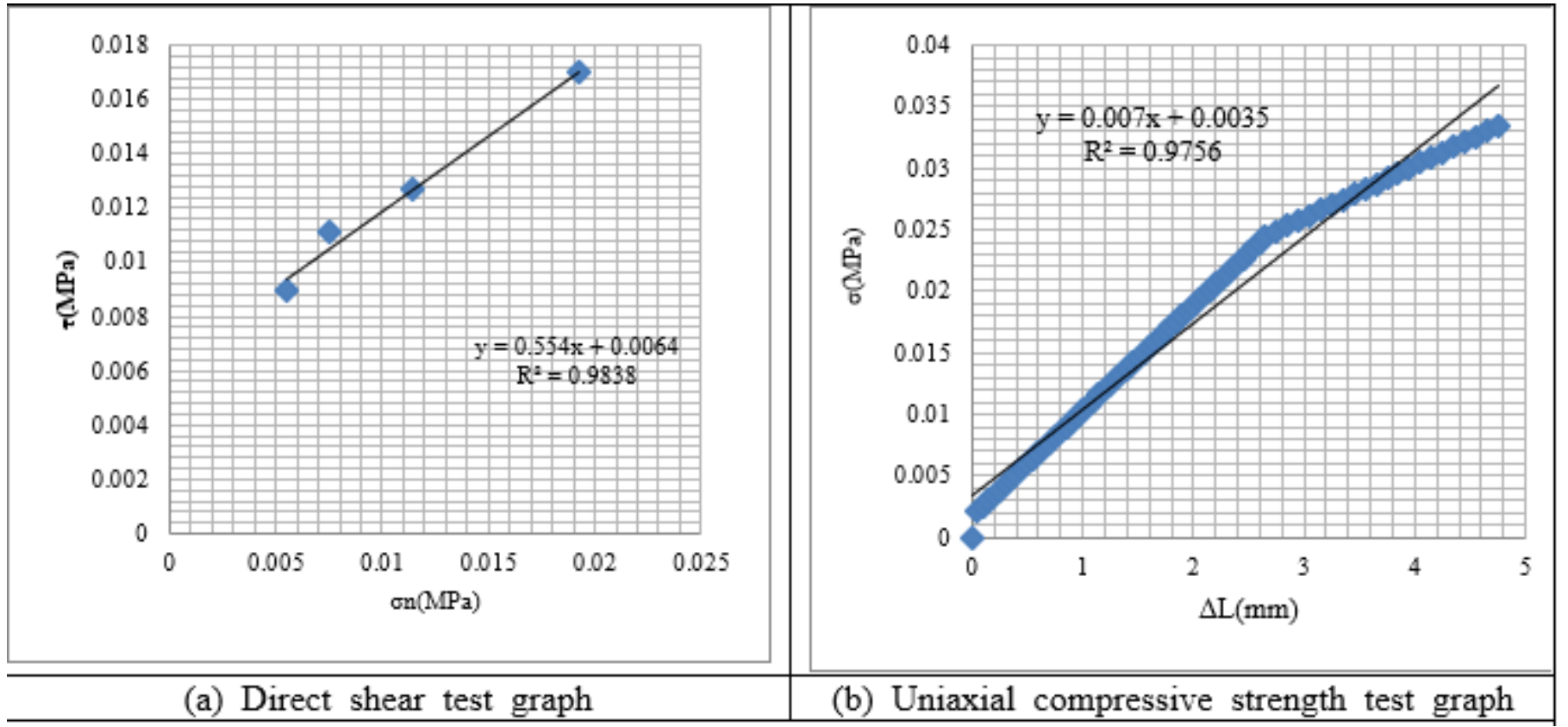

Figure 10

Geotechnical tests diagrams for soil 


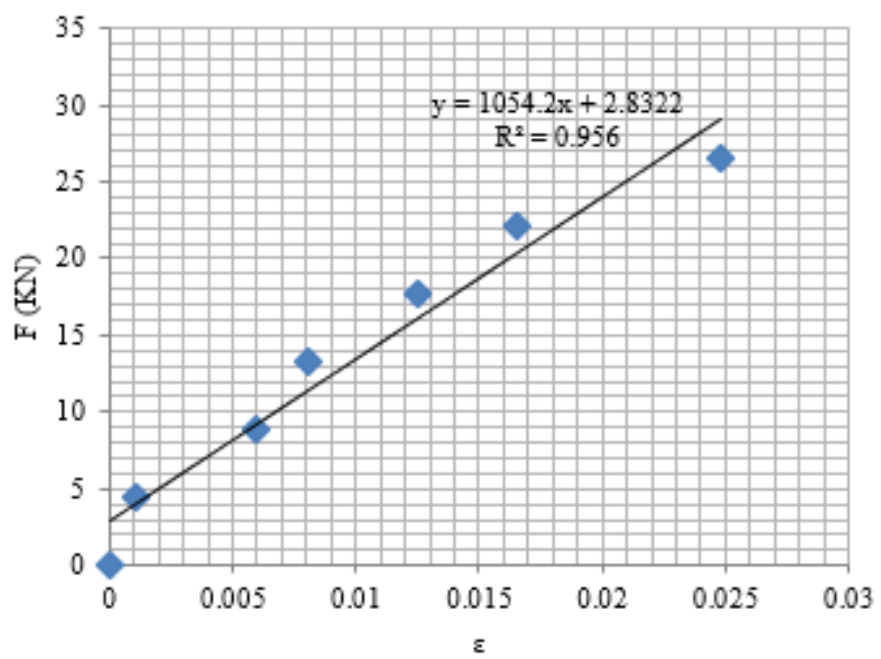

\section{Figure 11}

Uniaxial compressive strength test graph for the pile with 2.5(cm) diameter

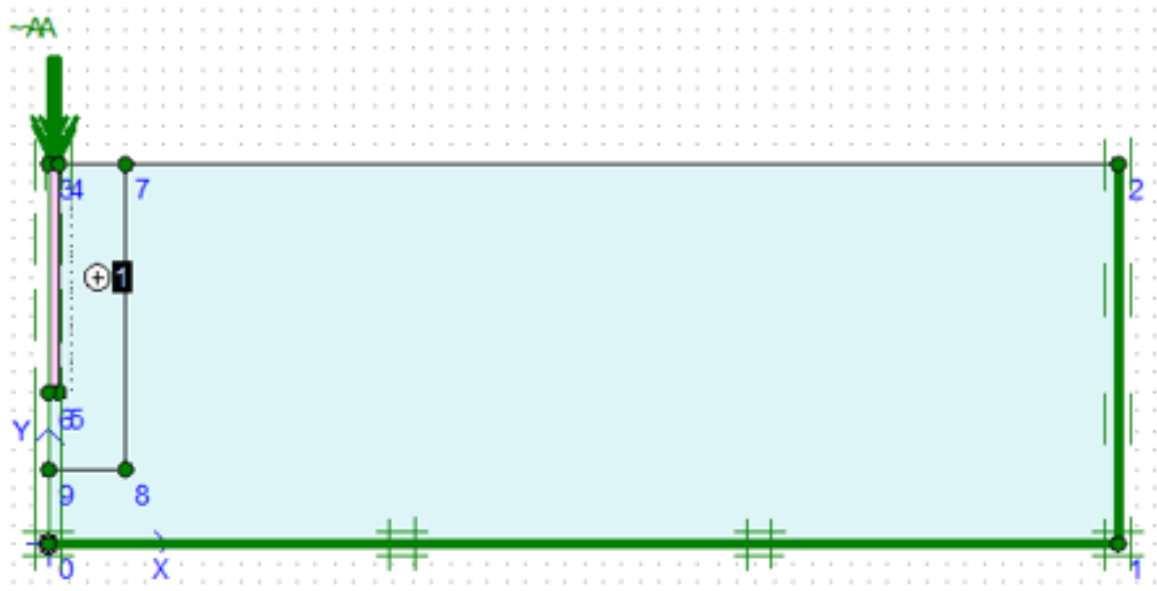

Figure 12

Axisymmetric model 


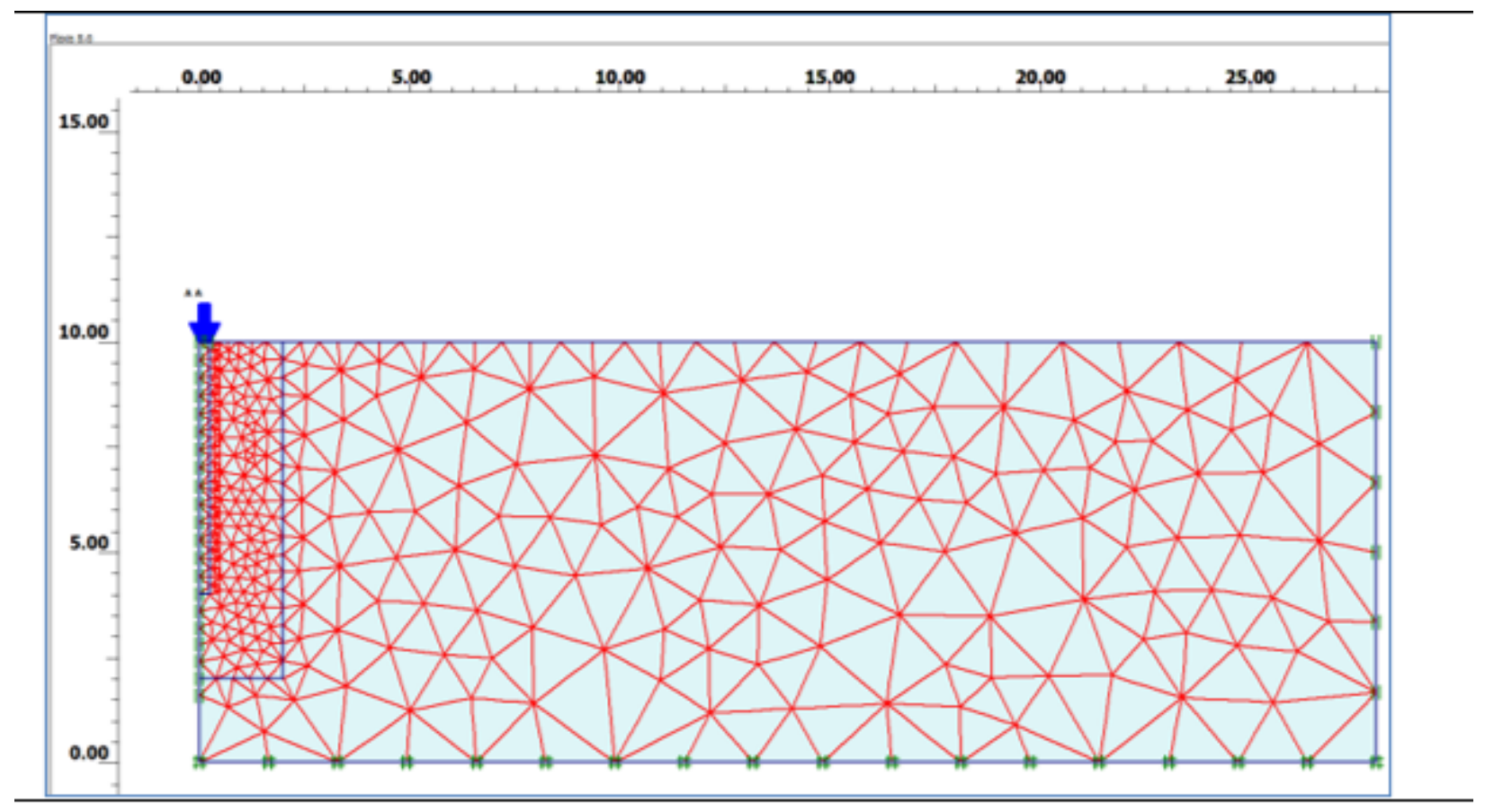

Figure 13

Mesh generation

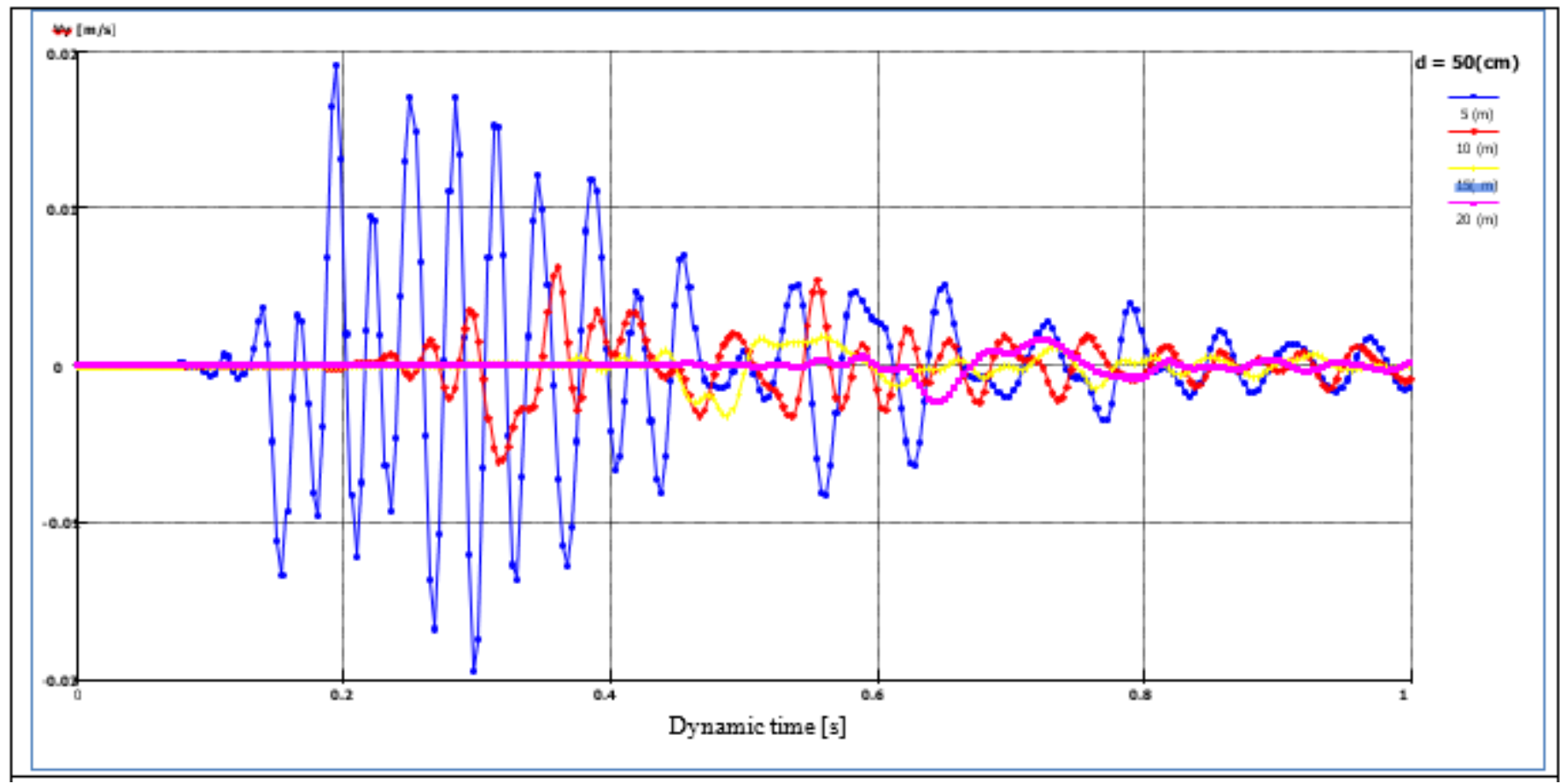

Figure 14

Velocity-time curve 


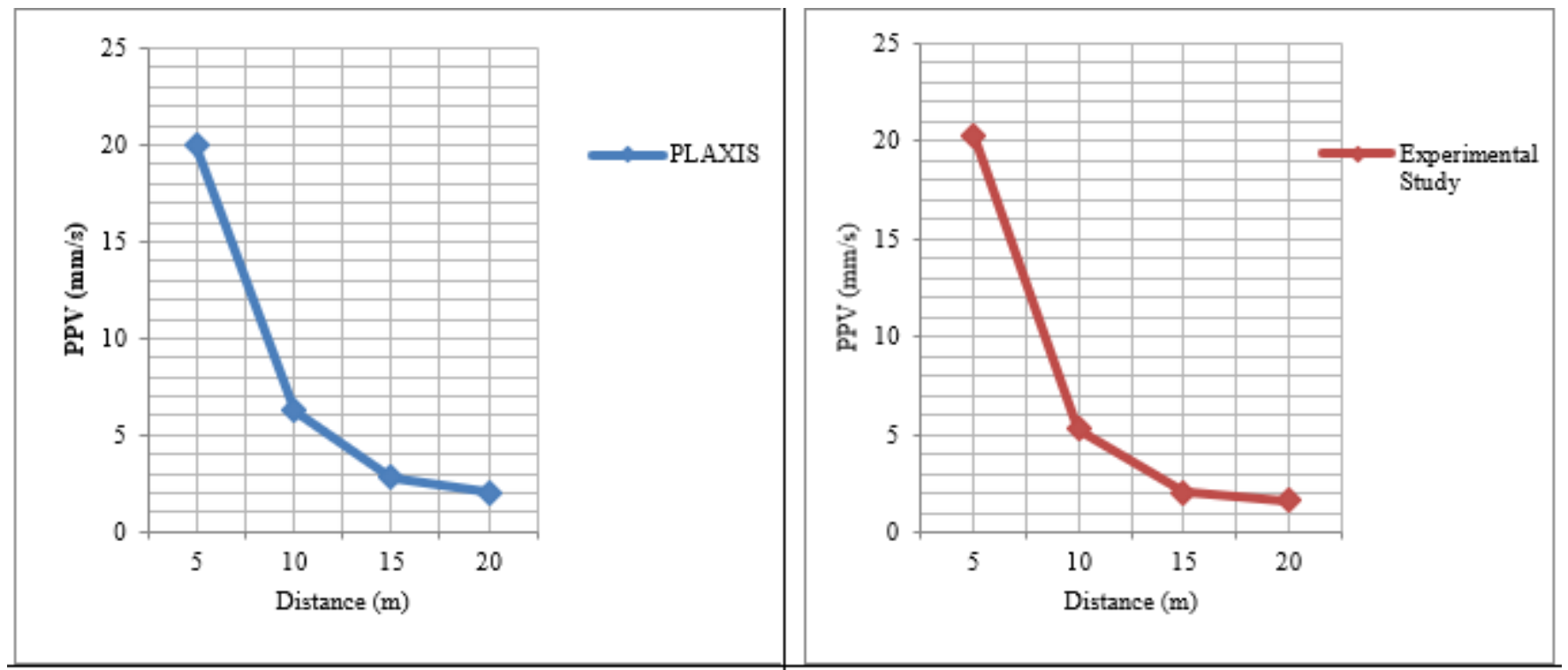

(a) Computed PPV values in PLAXIS

(b) PPV values in experimental study

\section{Figure 15}

Obtained PPV values from numerical simulation and experimental study

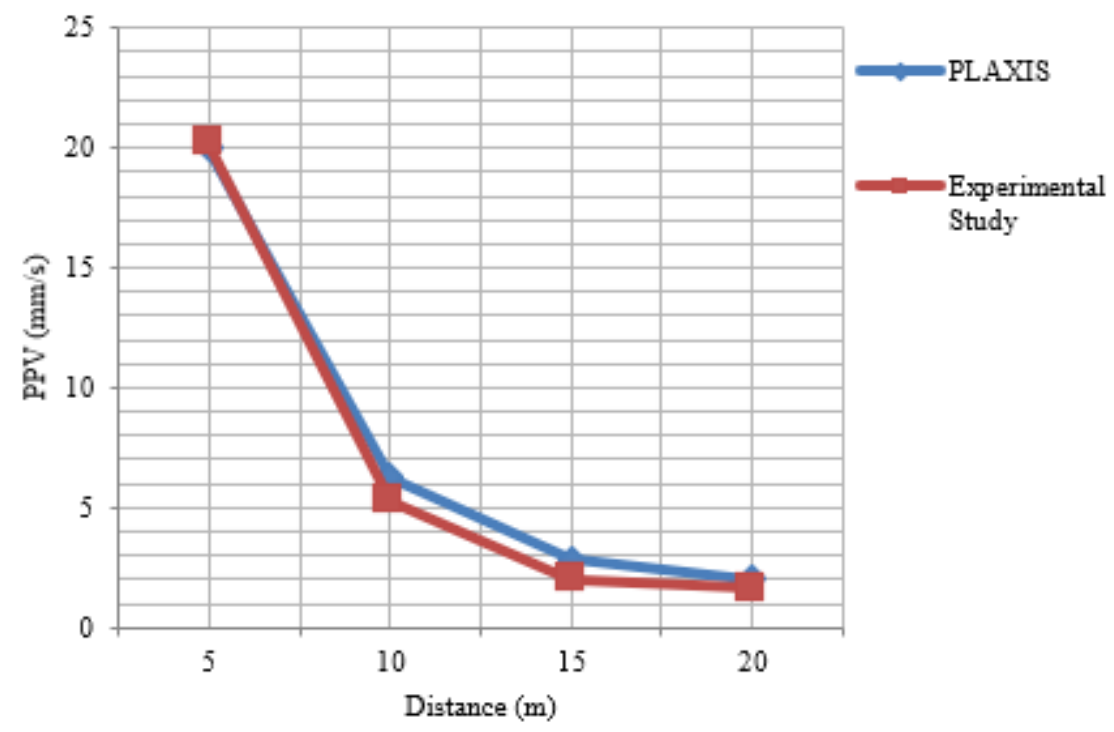

Figure 16

Comparison of PPV values obtained from numerical simulation and experimental study 


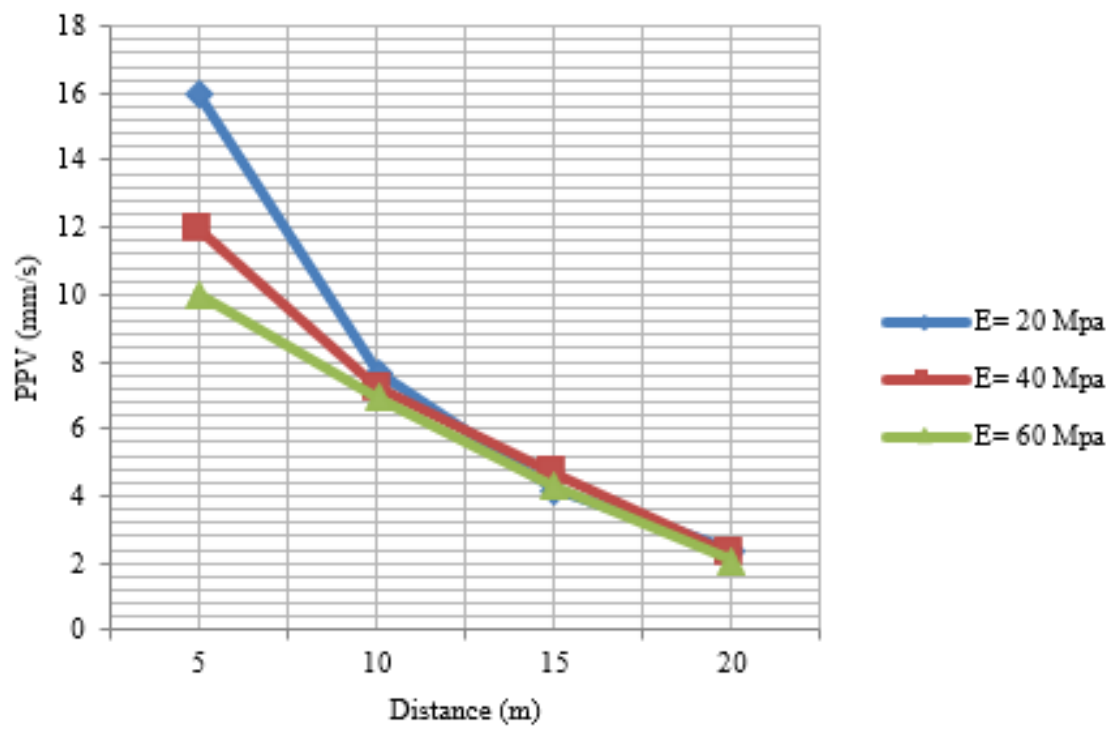

Figure 17

Computed PPV values for ground surface point for various elastic moduli

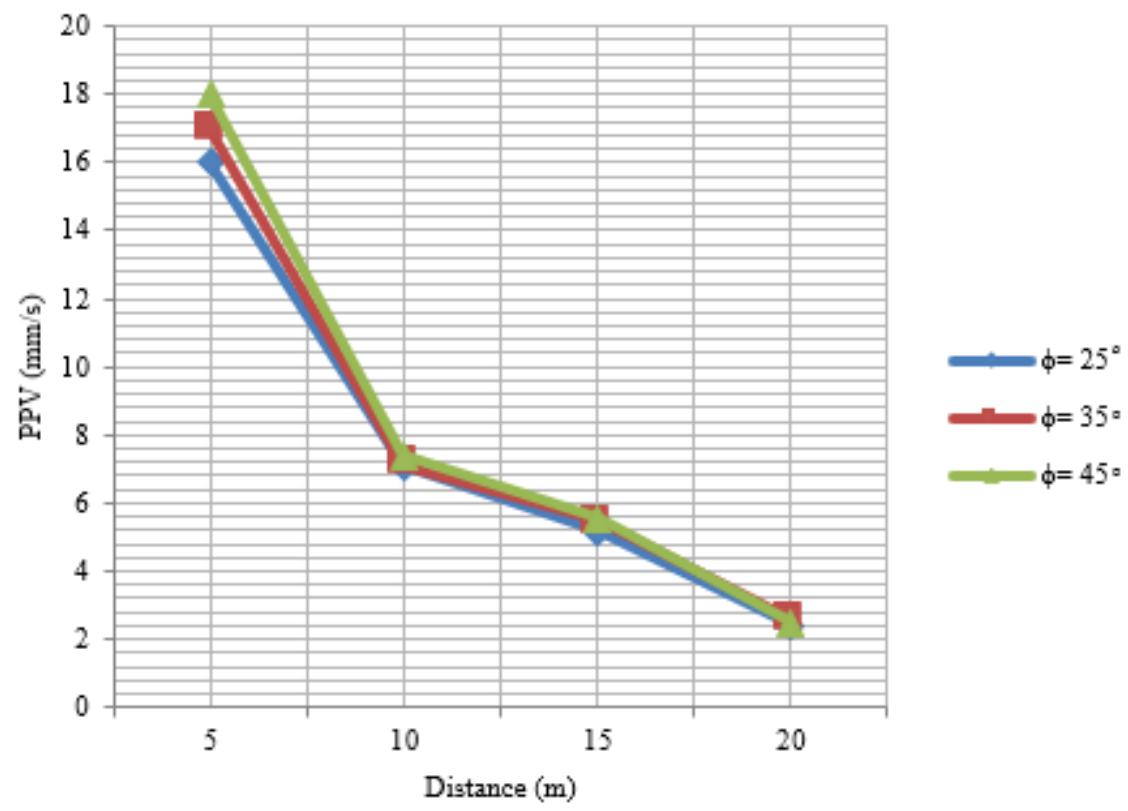

\section{Figure 18}

PPV values at ground surface points for various friction angles 


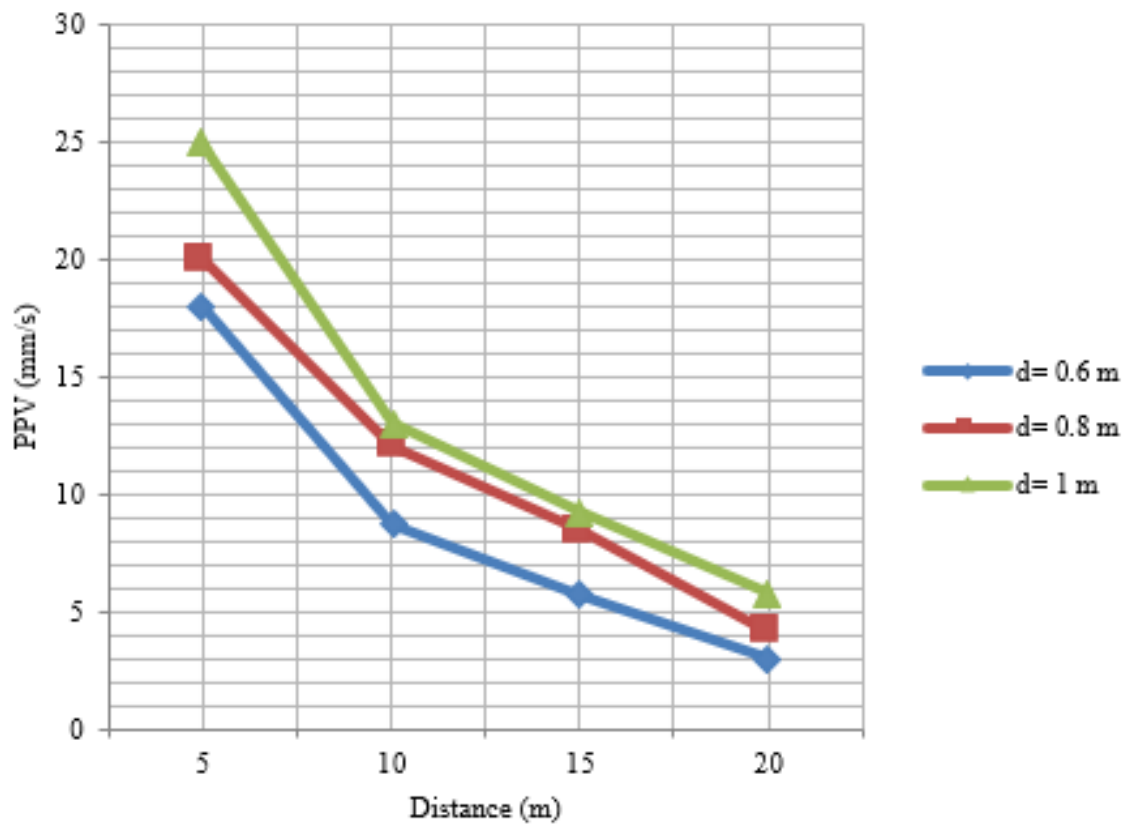

Figure 19

Computed PPV values at ground surface points for various pile diameters 